DOI: $10.15503 /$ jecs20162.217.229

\title{
EVALUATION OF THE PSYCHOMETRIC PROPERTIES OF SOGS-RA IN THE POLISH VERSION
}

\author{
JOLANTA JARCZYŃSKA
}

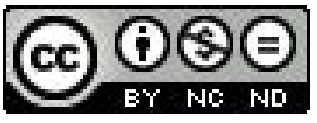

Katedra Pedagogiki Opiekuńczej i Profilaktyki Społecznej

Uniwersytet Kazimierza Wielkiego w Bydgoszczy

ul. J. K. Chodkiewicza 30, Bydgoszcz, Poland

E-mail address: jjarczynska@onet.eu

\begin{abstract}
Objective: The objective was to adapt the American pathological gambling screening tool /SOGS-RA The South Oaks Gambling Screen - Revised for Adolescent/ by K. Winters, R. Stinchfield and J. Fulkerson (1993) and to evaluate its psychometric properties.

Method: The adapted tool was used in research on a randomly selected sample of 2,617 adolescents aged 13-20 years in the 2012/2013 school year.

Results: On the SOGS-RA scale, $2.6 \%$ of the trial participants achieved a score indicating past year problem gambling before the survey, $4.1 \%$ were classified as problem gamblers, whereas $17.3 \%$ of adolescents engaged in social gambling that did not pose a problem gambling risk at the time. The SOGS-RA demonstrated satisfactory internal consistency (Cronbach's alpha $=0.78$ ).

Conclusions: The Polish adaptation of the SOGS-RA scale is reliable and accurate, which is why it is worth recommending it for use in further research on Polish adolescents.

Key words: problem gambling, pathological gambling, youth, games of chance, gambling, psychometric properties, SOGS-RA, screening tool
\end{abstract}

\section{INTRODUCTION}

The problem of gambling, which until recently was unnoticeable in Poland, is beginning to escalate very fast both in the adult and the teen populations. As many as 3.9\% of Polish adults are problem gamblers or are addicted to various kinds of games of chance (Malczewski, 2011a, 2011b, 2011c, 2012; CBOS, 2011). The 2011 ESPAD survey results show that approximately $2 \%$ of adolescents may be at risk of problem gambling (Sierosławski, 2011), whereas, based on the study conducted in 2013 by the CBOS Public Opinion Research Centre and the National Bureau for Drug Prevention in Poland on a sample of juveniles aged 18-19 years, $4.5 \%$ of the respondents revealed a high risk of gambling addiction. A moderate risk of gambling addiction was found 
to concern $9.2 \%$ of the respondents. Boys were found to have a higher risk of developing a gambling addition (7.5\% in boys with a high risk of addition and $12.8 \%$ in persons with a moderate risk of addiction) than girls (5.5\% for girls with a high risk of addition and $13.1 \%$ for persons with moderate risk of addiction) (Malczewski, 2014). The differences in the presented values most probably result from the use of a different research methodology and tools used to measure the gambling addiction risk. The 2013 studies of the CBOS Public Opinion Research Centre and National Bureau for Drug Prevention in Poland assessing the risk of becoming addicted to gambling used questions from the Canadian Problem Gambling Index (CPGI), whereas the ESPAD 2011 studies only asked two questions concerning two problem gaming indicators. The first question concerned the need to continuously increase the stakes in gambling, and the second was about lying about or hiding the extent of the gambling problem to somebody that was of importance to the respondent. This example shows the data inconsistencies, low reliability of obtained results and the difficulties in assessing the actual scale of problem gambling in the population of youth in Poland. Although we know more about the screening tests to measure problem gaming among adolescent school pupils used around the world (e.g. DSM-IV-MR-J; Fisher, 2000; MAGS (Shaffer, LaBrie, Scanlan, \& Cummings, 1994, CAGI), we still lack Polish adaptations of such instruments that would be accurate and proven through validation tests. Work on the development or adaptation of foreign screening tests concerning teen problem gaming has only just recently been undertaken, which means that the process of construing a set of instruments diagnosing this phenomenon affecting young people is still in its early stages and requires further and more advanced work. Effective screening tools that would enable fast and easy identification of youth groups engaged in risky gambling behaviour or young people whose participation in this activity has become the source of serious problems (i.e. problem and pathological gamblers) are required. With this aim, the first attempts of adapting the SOGS-RA scale by K. Winters, R. Stinchfield and J. Fulkerson (1993) have been undertaken in Poland. Their course and outcomes are presented below.

\section{METHOD}

The aim of this study was the adaptation and validation (reliability, as well as criterion and theoretical validity assessment) of one of the most popular tools in the world for screening pathological gambling among young persons, namely, the SOGS-RA (The South Oaks Gambling Screen - Revised for Adolescents) by K. Winters, R. Stinchfield and J. Fulkerson (1993). The scope of the study included:

- The adaptation of the SOGS-RA scale for screening problem and pathological gambling among school pupils (lower and upper secondary school); 
- The performance of pilot and proper studies in order to account for the cultural differences and to evaluate the psychometric properties of the instrument;

- The validation of the adapted tool/screening test.

The end result of the study is the Polish adaptation of the American screening tool /SOGS-RA/ with confirmed psychometric properties (verified in two stages encompassing the pilot and proper study).

The research was co-financed from the Fund for Solving Gambling Problems (FRPH), grant numbers: 39/I/H/12, 3/I/H/K/E/2013. The studies have provided a better insight into and description of the phenomenon of risky and problem gambling among youth, helping to fill knowledge gaps about the gambling behaviour of teenagers.

The proper study was performed at the turn of February/early March 2013 on a sample of 2,617 pupils. The research was preceded by a pilot study on a sample of 591 pupils in December 2012. A total 2,579 surveys were included in statistical analyses during the second, proper study stage. Substantial data deficiencies, inconsistent responses, humorous entries and other information suggesting that the respondents failed to treat the surveys seriously led to 38 surveys being considered unreliable. The study population consisted of adolescents aged 13-20 years, general lower and general upper school secondary school pupils in the 2012/2013 school year in the City and District of Bydgoszcz. The mean age of the respondents was $15.7+1.3$ years. Respondents were selected using a random, multi-layered design. The first stage involved the random sampling of towns and villages from within the Bydgoszcz district, followed by the selection of lower and upper secondary schools, and finally the drawing of school forms. A school form constituted the basic sampling unit. The study encompassed form one, two and three general lower secondary school pupils and upper secondary school pupils (from all the available types of upper secondary schools: general secondary schools, technical secondary schools and basic vocational schools) from all forms: first, second, third and fourth, in the case of technical secondary schools. The sample drawn consisted of 14 general lower secondary schools, 8 general upper secondary schools, 5 technical secondary schools and 4 basic vocational schools. The largest percentage of respondents within the sample were general lower secondary school pupils $(46 \%, N=1,188)$, and the lowest percentage constituted basic vocational school pupils $(5 \%, N=128)$. Respondents attending general upper secondary schools accounted for $27 \%(\mathrm{~N}=688)$, and $22 \%(\mathrm{~N}=575)$ were from technical secondary schools. Girls/women made up $51 \%(\mathrm{~N}=1,309)$ of the respondents and boys $49 \%(\mathrm{~N}=1,267)$ of the respondents.

The survey was anonymous and voluntary, conducted by means of a random survey. The surveys were completed individually during school lessons. The respondents were informed about the subject and aims of the study and that participation was anonymous and voluntary. To ensure the survey was anonymous, respondents were asked not to include their first or last names on the surveys. They were informed that gambling is an action that 
contains an element of risk, which involves the pledge of money or material goods that can be won or lost. Winning depends on chance alone. Different forms of gambling activities were described to the pupils to make them more aware that gambling is not limited to casino games alone. The respondents were interviewed by an employee of the KazimierzWielki University and trained second-year, full-time students of Childcare Education at the Faculty of Education and Psychology at the KazimierzWielki University in Bydgoszcz, not associated in any way with the schools in which the surveys were conducted. One interviewer was present in each class during the survey. The interviewers answered questions from the participants and fostered the right atmosphere during the survey. Teachers were asked to leave the class. The average time to complete the questionnaire was 15 minutes.

The following statistical techniques were applied to analyse and prepare the statistical results:

- The reliability of the SOGS-RA scale was evaluated by calculating the Cronbach's alpha reliability coefficient;

- The validity of the SOGS-RA scale was assessed using two methods of measurement: criterion validity using Spearman's rank correlation coefficient and point biserial correlation coefficient (rpb) and theoretical validity with the SOGS-RA single-factor structure scale provided by the authors (Winters et al, 1993). Confirmatory factor analysis (CFA) was applied for this purpose. A statistical analysis of the results was performed using the STATISTICA 10 software package.

\section{WORK ON THE POLISH ADAPTATION OF THE SOGS-RA SCALE AND ITS USE IN STUDIES OF SCHOOL-AGED YOUTH}

As already mentioned above, there are no domestic or foreign adaptations of youth gambling screening tests available in Poland. The main purpose of the research was to adapt the SOGS-RA scale to existing cultural conditions and verifying its reliability and relevance in the surveyed group of teenagers. Formal considerations consisting of obtaining the scale's authors' (Winters, Stinchfield, \& Fulkerson) consent for its free-of-charge use in Polish research and co-funding for the performance of its adaptation work from the Fund for Solving Gambling Problems (FRPH) administered by the Minister of Health were mainly at play in the selection of this very instrument. The knowledge gathered from literature on the subject confirming the popularity and usefulness of the SOGS-RA scale in research on problem gambling among adolescents around the world as well as the data indicating its satisfactory psychometric properties were important elements justifying the use of this scale. It was shown on the basis of a review of literature that the SOGS-RA scale was used in a number of studies, including in Ontario (Govoni, Rupcich, \& Frisch, 1996), Louisiana (Westphal, Rush, Stevens, \& Johnson, 2000), Manitoba (Wiebe, 1999; Wiebe, Cox, \&Mehmel, 2000), the Atlantic coast of Canada 
(Poulin, 2000), Oregon (Carlson \& Moore, 1998), and Lithuania (quoted after: Stinchfield et al., 2004; Skokauskas et al., 2009). It has been recognised as one of the most popular, robust and reliable measurement methods serving the identification of problem gambling among youth. The internal consistency of the scale has been reported by all authors. The reliability of the scale measured using Cronbach's alpha has been demonstrated throughout publications as ranging between $0.70-0.80$. The authors of the instruments (Winters, Stinchfield, \& Fulkerson,1993, 2000) demonstrated its satisfactory reliability (0.80) calculated exclusively for a group of 460 boys aged 15-18 years (quoted after: Stinchfield, 2011; Derevensky, \& Gupta, 2004). Extensive research performed on the Atlantic coast of Canada in 1998 on a sample of 13,549 adolescents (the average age of study participants being 15.2 years, where $50 \%$ of the respondents constituted boys) attending general lower and upper secondary schools located in four of Canada's Atlantic provinces confirmed the satisfactory internal consistency of the SOGS-RA scale, separately for the groups of girls (0.76) and boys (0.81) (Poulin, 2002). The SOGS-RA scale was also applied in studies conducted in Lithuania. The tool was used to test a group of 835 adolescents aged from 10 to 18 years (the average age being $14.5 \pm 2.2$ years), confirming its reliability with Cronbach's alpha levels of $0.75=$ (Skokauskas et al., 2009).

Nevertheless, it would also be worthwhile to mention some of the flaws of this tool that were pointed out by some researchers. Several scientists claim that SOGS-RA tends to overestimate the prevalence of pathological gambling in the whole population (Abbott, \&Volberg, 1996; Ladouceur et al., 2000). Ferris et al. (1999) argue that the tool was not tested adequately enough on the sample of girls, which resulted in the appearance of a low prevalence of problem gamblers among teenage girls during the general test. However, according to Derevensky and Gupta (2004), these kinds of problems have been found in the majority of instruments aimed at adolescents. Poulin argued that the threshold for pathological gambling that has been set in SOGS-RA leads to a much greater incidence of pathological gamblers among men playing every day than women playing with the same frequency (Poulin, 2002). Therefore, it would be worthwhile to conduct parallel studies on the prevalence of problem gambling among Polish secondary school pupils using an alternative, recognised screening test (e.g. DSM-IV-MR-J or CAGI), however, no Polish versions of such instruments are available yet as work has just been undertaken on their adaptation.

The South Oaks Gambling Screen - Revised for Adolescents (SOGS-RA) (Winters et al., 1993) is an updated version of The South Oaks Gambling Screen (SOGS) (Lesieur\&Blume, 1987). Winters, Stinchfield and Fulkerson revised SOGS in 1993 to apply the scale to adolescents in Minnesota and they called their revised scale the SOGS-RA (SOGS - Revised for Adolescents). The SOGS-RA was developed as a screening tool to ensure more accurate evaluation of the severity of problem gambling among young people. It is a 16-item scale (four items/questions are not scored), which evaluates gam- 
bling behaviour in the past year and resulting problems. The tool enables the identification of regular and occasional gamblers. Statements taken from the original SOGS were revised, making them more relevant to the age of the studied sample of teenagers, as well as to their habits and reasoning skills. The original result scoring scheme was also modified. The changes in the scoring system were implemented on items relating to the sources of money borrowed for gambling. Teenagers are now only given one point for each source of borrowed money, whereas in the original SOGS version they could obtain as many as 9 points ( 1 point for each indicated source). The screening test focuses on the frequency of gambling behaviour and the behavioural indicators that often accompany problem gambling rather than on the financial losses incurred (which were greatly emphasised in the original SOGS) (Derevensky, \& Gupta, 2004).

The SOGS-RA is used to obtain a much more accurate assessment of problem gambling in adolescence and facilitates the classification of respondents to particular categories. A score of 0 points means a "gambling teetotaller", meaning a person that played no games of chance during the past year (does not play); 1 point indicates a non-problem gambler (i.e., a person that played games of chance at the time, but his/her involvement in this form of activity was predominantly entertainment-like and the person failed to experience any negative consequences of gambling). Scores ranging from 2 to 3 points indicate a player demonstrating risky gambling behaviour (when they start identifying the first, more serious and negative consequences of their gambling), and the score of 4 or more points identifies "problem gamblers" (individuals who feel compelled to play and experience a number of serious consequences of gambling). This tool is currently considered to be the most popular, accurate and reliable measurement method and screening tool identifying problem gambling in adolescents (Shaffer, \& Hall, 1996; Wiebe et al.; 2001, Winters et al.; 1993, Stinchfield, 2011). The reliability and relevance coefficients of the tool were calculated for a group of 460 boys aged 15-18. The reliability of the scale was Cronbach's alpha $=0.80$ (Stinchfield, 2011; Derevensky, \& Gupta, 2004). In order to measure the internal validity of the instrument, SOGS-RA was correlated with gambling activity $(r=0.39)$, gambling frequency $(\mathrm{r}=0.54)$ and the amount of money spent on gambling during the course of the past year $(\mathrm{r}=0.42)$ (Winters, Stinchfield, \& Fulkerson, 1993).

The Polish version of the SOGS-RA was adapted by J. Jarczyńska. All the questions included in it are the Polish adaptation of the Canadian SOGS-RA scale by Winters, Stinchfield, and Fulkerson (1993). During the adaptation process, the authors of the Polish version verified the adequacy of the wording of the questions to our cultural environment as well as their understanding by school-age youth. A pilot study was conducted for this purpose, which confirmed the adequacy of the Polish questionnaire. The study was conducted on a sample of 591 pupils. The SOGS-RA scale was translated into the Polish language and then back into English. Two 
translators compared the translated text with the source text and the findings suggest that the translated questions demonstrate great similarity in meaning to their English equivalents. The results of the pilot study have shown that the questions and statements entailed in the wording including the response categories are comprehensible, clear and unequivocal for the studied adolescents.

The SOGS-RA consists of 16 items/questions (four items/questions are omitted for scoring. These items/questions include 1, 2, 3, and 4), just as in the original version of the scale. The remaining 12 questions are have a zero-one scoring. The total score range of the scale is from 0 to 12 points. The higher the score value on the scale, the greater the severity of problem gambling among the studied individuals. A result of 0 to 1 points indicates that a player is not at risk of problem gambling. A value ranging from 2 to 3 points means that a player is at risk of problem gambling, and the award of 4 or more points indicates a problem gambler. The test allows for gambling-related behaviour and problems over a period of the last 12 months preceding the survey to be evaluated.

Questions 1 and 2 measure the changes in the severity of gambling problem among adolescents. The first question refers to both the number of gambling-related activities at least once in a lifetime and in the past 12 months. The original version of the instrument lists 11 gambling-related activities. The Polish list has been expanded by two additional items (participation in lotteries and phone-in or SMS quizzes, as well as Internet money gambling and online casinos). The analysis of gambling-related activities undertaken in the past 12 months before the survey helped to determine the overall frequency of gambling at this time and was calculated on the basis of the number of times the 13 listed gambling-related activities were undertaken. The increase in the frequency of each activity was measured on a scale of 1 to 5 . The possible responses were: never (1 pt.), less than once a month $(2$ pts.), once a month or more ( 3 pts.), once a week or more (4 pts.), and once a day - every day (5 pts.).

Question no. 2 of the survey questionnaire concerned the highest amount of money that a respondent ever risked/bet when gambling in the past 12 months. This was a closed-ended question with the following response options: never risked - (0 pts.), less than PLN $5^{1}(1 \mathrm{pt}$.), from 5 to 10 PLN (2 pts.), more than 10 PLN, up to 50 PLN (3 pts.), from 50 to 100 PLN (4 pts.), from 100 to 200 PLN (5 pts.), from 200 to 500 PLN (6 pts.), and more than 500 PLN (7 pts.).

\section{RESULTS}

A validation study evaluating the reliability of the SOGS-RA scale was conducted by examining its internal consistency and criterion and theoretical

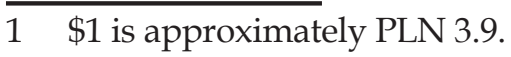


validity. Due to the J-shaped distribution obtained in the studies, the authors decided not use normalisation. Narrow SOGS-RA criteria were used to interpret the results, as proposed by its authors (Winters et al., 1993), which facilitates easy comparison of own results with the outcomes obtained by other researchers and allows the use of the same criteria when assessing the intensity of problem gambling among juveniles.

\section{RELIABILITY OF THE SOGS-RA SCALE IN THE POLISH ADAPTATION}

Internal consistency is a measure of the reliability of the scale used to evaluate the degree to which different test items produce similar results. The higher the Cronbach's alpha coefficient as an indicator of the internal consistency of the scale, the greater the reliability of the measurement. A value of the coefficient of 0.70 or higher is generally considered as admissible (Blacker, \& Endicott, 2002).

The calculations performed confirmed the reliability of the measurements using the SOGS-RA scale, which were double checked (after the pilot and proper studies). The SOGS-RA scale has satisfactory internal consistency (for the total sample: Cronbach's alpha for the pilot study $=0.79$, for the proper study $=0.78$; for the group of lower secondary school pupils: for the pilot study $=0.77$, for the proper study $=0.75$; and for the group of upper secondary school pupils (general secondary schools, technical secondary schools and basic vocational schools): in both the pilot and proper studies, Cronbach's alpha $=0.80$ ). The differentiating power of the scale items was within the range of 0.36 to 0.52 , and the average item intercorrelations were 0.26 .

By comparing the value of the Cronbach's alpha coefficient obtained with other researchers' results, it can be confirmed that a satisfactory value very close to the coefficient results of other researchers was achieved in the author's own research.

The reliability of SOGS-RA in the Polish adaptation was subjected to subsequent assessment in studies conducted at the turn of November/early December 2014 on a group of 641 general upper secondary school pupils aged 15-22 years in Poland. These pupils attended general secondary schools $(\mathrm{N}=220)$, technical secondary schools $(\mathrm{N}=241)$ and basic vocational schools $(\mathrm{N}=180)$. The average age of the respondents was 16.9 years. Boys/men constituted the largest group of the respondents $(\mathrm{N}=360)$ compared to girls/ women $(\mathrm{N}=270)$. After disqualifying 12 questionnaires due to shortcomings in data required for statistical analysis, a total 629 questionnaires were successfully qualified. The results obtained on the SOGS-RA scale for all the respondents confirm its high reliability, Cronbach's alpha $=0.87$. The average correlation between items amounted to 0.39 . 


\section{VALIDITY OF THE SOGS-RA SCALE IN THE POLISH ADAPTATION}

The criterion validity of the instrument and other scales described below was evaluated by correlating gambling frequency and money spent on gambling in the last year (as performed by Winters, Stinchfield, \& Fulkerson, 1993).

First, the relationship between the SOGS-RA scale and gambling frequency in the lifetime was investigated (in Polish: CGHŻ) compared to gambling frequency within the past year (in Polish: CGHR), and the increased frequency scale of gambling over the past year (in Polish: ZCGHR). The internal consistency of each scale (Cronbach's alpha for the CGHŻ scale $=0.76$; for the CGHR scale $=0.85$, for the ZCGHR scale $=0.76$, and for the SOGS-RA scale $=0.78)$ was evaluated. Due to the strong asymmetry of SOGS-RA sample distributions, Spearman's rank correlation coefficient was applied. There is a moderate, statistically significant correlation between the SOGS-RA scale and the scale of gambling frequency within the past year (CGHR) $(0.49, p<0.001)$, the scale of the increased frequency of gambling over the past year $(\mathrm{ZCGHR})(0.46, \mathrm{p}<0.001)$, and the scale of gambling frequency in the lifetime (CGHŻ) $(0.43, \mathrm{p}<0.001)$.

In addition, the criterion validity of the scale was tested by calculating the correlation between the SOGS-RA scale and the three additional questions included in the questionnaire. These questions concerned the amounts of money spent on gambling by a respondent within a period of one month; whether the respondent felt compelled to return to gambling after winning to further increase his/her winnings, and the loss of control of gambling expenditures where respondents would continue gambling until their last penny is spent. The results of the analysis demonstrate that the SOGS-RA scale had the strongest correlation with the question concerning gambling expenditures over a period of one month $(0.51, \mathrm{p}<0.001)$.

While assessing the criterion validity of the SOGS-RA scale, the relationship between the scale and the two other survey questions was investigated. These two questions were dichotomous which is why a point-biserial correlation coefficient was applied (rpb). The aim of the first question was to determine whether a respondent felt the need to continue gambling after winning, in order to increase his/her winnings $(\mathrm{rpb}=0.46, \mathrm{p}$ $<0.001$ ). The other question concerned the loss of control over gambling expenditures. The respondent was asked whether he/she often spent their last penny on gambling $(\mathrm{rpb}=0.45, \mathrm{p}<0.001)$. The values obtained indicate that the SOGS-RA scale strongly correlates with both the first and the second question.

The authors of the instrument (Winters, Stinchfield, \& Fulkerson), examined the relevance of the tool by correlating the SOGS-RA scale (using Pearson's linear correlation coefficient) with the types of gambling that the tested individuals were engaging in throughout their lives $(r=0.39)$ and during 
the past 12 months (0.39), the increased frequency of gambling in the past year $(\mathrm{r}=0.54)$, and the amount of money spent on gambling in the previous year $(r=0.42)$. The correlations were statistically significant $(p<0.01)$ (Winters, Stinchfield, \& Fulkerson, 1993a). The correlation coefficients obtained by them were clearly similar to the ones presented above.

In assessing the theoretical validity of the SOGS-RA scale, a single-factor structure of the scale assumed by its authors (Winters et al, 1993) was also examined. For this purpose, confirmatory factor analysis (CFA) was applied. The assumed single-factor model was confirmed by empirical data. The goodness-of-fit of the model proved to be satisfactory. The chi-squared value was 934.681, $\mathrm{p}<0.01$. Due to the great significance of the study sample $(\mathrm{N}=$ 2.579) it can be acknowledged that it is not a decisive indicator, which does not mean that the single-factor model should be abandoned. The goodness-of-fit statistics demonstrate the satisfactory fit of the univariate model to the empirical data: $\mathrm{RMSEA}=0.08$ and GFI $=0.94$.

The results of the research helped estimate the scale of the problem gambling threat among adolescents. The vast majority of respondents $(90 \%$, $\mathrm{N}=2,314$ ) tried gambling or played games of chance at least once in their lifetime. In the group of individuals who never gambled or played games of chance $(10 \%, N=256)$, girls/women represented a slight majority of $54 \%$ $(\mathrm{N}=138)$.

On the SOGS-RA scale, $2.6 \%$ of the study participants $(\mathrm{N}=67)$ achieved a score indicating past year problem gambling, 4.1\% ( $\mathrm{N}=105)$ were classified as problem gamblers, whereas $17.3 \%$ of adolescents $(\mathrm{N}=445)$ engaged in social gambling that did not constitute a gambling problem risk at the time, while the vast majority, namely, $76 \%(\mathrm{~N}=1,945)$ reported no involvement in games of chance over the past year. Among the persons who had not played games of chance at the time, there were more girls than boys $(56 \%, \mathrm{~N}=1,094$ vs. $43 \%, \mathrm{~N}=851)$. The results obtained by problem gamblers ranged from 4 to 12 points, with an average of $5.7 \pm 0.88$ and a median of 5 . The standard deviation value was 1.977 . The results obtained by "at-risk" players ranged from 2 to 3 points, with the average of $3.3 \pm$ 0.4 and a median of 3 . It is worth pointing out that there were more girls/ women, as many as $54 \%(\mathrm{~N}=138)$ in the group of persons who have never tried gambling $(10 \%, \mathrm{~N}=256)$.

In the sample of 641 upper secondary school pupils that took part in the above mentioned study conducted in 2014 in Poland, 9.22\% (N=58) of the respondents that were classified as problem gamblers all of which obtained a result of 4 or more points on the SOGS-RA scale. The largest number of these respondents were pupils from basic vocational schools $(14.5 \%$; $N=26)$, then technical secondary schools $(8.4 \%, \mathrm{~N}=20)$ and lastly general secondary schools $(5.6 \%, \mathrm{~N}=12)$. There were more boys/men in the group involved in gambling than girls/women. 


\section{DISCUSSION}

The Polish version of the SOGS-RA proved its satisfactory reliability and validity in the study under discussion. However, as in the case of every study, this study had its limitations, which are worth considering when interpreting the results. Firstly, the study was only based on the information provided by the respondents themselves. However, this is the standard approach in such studies. Secondly, the data had been gathered in schools, which means that the conclusions only concerned school-age youth, and thirdly, the study was not conducted on a national sample or respondents. Therefore, the results are only representative of one region in Poland. While applying the SOGS-RA scale, it would also be useful to expand the reach of the survey and attempt to cover a nationwide sample of Polish adolescent pupils in order the make a preliminary diagnosis of the problem. A comparison of study results on the SOGS-RA scale with the results obtained using different tools like the DSM-IV-MR-J or CAGI could also be performed to confirm the validity of the study and the outcomes of earlier research different tools. A limiting factor preventing such comparisons is the already mentioned fact that these tests have not yet been adapted in Poland. There is a great hope, however, that the translation of these instruments into the Polish language will soon be undertaken and subjected to validation. Such studies can be undertaken under the provisions of the Regulation of the Minister of Health that came into force on 25 January 2011, which lays down the terms and conditions on which expenditure can be covered by the Fund for Solving Gambling Problems. This is a state fund whose revenues come from $3 \%$ of the payments to gambling. These funds are allocated under the Act to the conduct of informational and educational activities and campaigns as well as for the preparation of expert opinions and reports concerning the problem of addiction to gambling. They are also used to design and implement new methods of preventing gambling addiction and resolving the numerous problems that it creates. It also supports initiatives aimed at improving the quality of preventive and therapeutic programs, as well as training counsellors and other professionals involved in the treatment of persons affected by problem gambling.

It would also be worth including an assessment of the occurrence of other areas of problematic behaviour such as high-risk behaviour, particularly the use of psychoactive substances and other known risk factors (e.g. impulsiveness), in order to see whether or not they correlate in line with the direction found in earlier studies.

Such projects are worth initiating, since it is estimated that youth participation in games of chance in Poland may well be on the rise. Over the last several years, the availability of slot machine centres has greatly increased and the very accessibility of the Internet itself with its strong emphasis on the promotion of games of chance and gambling, headed by the Polish National Lottery, as well the numerous other lotteries and SMS competitions organized by mobile network operators, television, radio stations and betting 
companies is further exacerbating the problem. Due to the low opening bet amounts, slot machines are available even for people with limited cash resources, like, for instance, adolescents. Therefore, further research is vital to monitor the frequency of problem gambling in school-age youth in Poland. This study has undoubtedly provided an important reference point for further research. The SOGS-RA scale in the Polish adaptation is recommended for screening problem gambling among school-age adolescents. The tool has proven psychometric properties and allows for the quick and early identification of individuals playing for fun, as well as "at-risk" players and problem gamblers. Furthermore, it allows an easy and fast initial diagnosis of the risk groups (i.e., people facing "at-risk" playing and problem gambling), identification of the number and type of problems and the extent of damage suffered by young people in connection with their participation in different types of gambling/games of chance and, finally, evaluation of the frequency of playing these games during a lifetime and in the past year. Screening tests using this tool can provide a starting point for further in-depth diagnostic and clinical research. Early identification of risky gambling and of the threat of problem gambling allow rapid intervention and support activities for individuals at risk of problem gambling who have already experienced the first negative consequences of their own actions (social, psychological, health-related, economic, etc.).

\section{REFERENCES}

[1] Abbott, M., \& Volberg, R. (1996). The New Zealand National Survey of Problem and Pathological Gambling. Journal of Gambling Studies, 12(2), pp.143-159.

[2] Blacker, D., \& Endicott, J. (2002). Psychometric properties: Concepts of reliability and validity. In: A. J. Rush, H. A. Pincus, \& M. B. First (Eds.), Handbook of psychiatric measures. Washington: American Psychiatric Association (CD-ROM).

[3] Carlson, M.J., \& Moore, T.L. (1998). Adolescent Gambling in Oregon. Salem, OR: Oregon Gambling Addiction Treatment Foundation. Retrieved from: http://www.gamblingaddiction.org/

[4] Centrum Badania Opinii Społecznej, BS/64/2011: Polak w szponach hazardu. Retrieved from: http://www.cbos.pl/SPISKOM.POL/2011/K_064_11.PDF

[5] Derevensky, J.L., \& Gupta, R. (2004). The measurement of youth gambling problems. Current instruments, methodological issues, and future directions. In: J.L. Derevensky,

[6] N. Gupta (Ed.). Gambling Problems in Youth: Theoretical and Applied Perspectives.

[7] New York: Kluwer Academic/Plenum Publishers, pp. 121-143.

[8] Ferris, J., \& Wynne, H. (2000). Validating the Canadian Problem Gambling Index: Report on the Pilot Phase of Testing, January 10, 2000. Retrieved from: http:/ / www.ccsa.ca

[9] Ferris, J., Wynne, H., \& Single, E. (1999). Measuring problem gambling in Canada. Final Report Phase I. The Inter-Provincial Task Force on Problem Gambling.

[10] Govoni, R., Rupcich, N., \& Frisch, G.R. (1996). Gambling behavior of adolescent gamblers. Journal of Gambling Studies, 12 (3), pp. 305-317.

[11] Ladouceur, R., Bouchard, C., Rheaume, N., Jacques, C., Ferland, F., Leblond, J., \& Walker, M. (2000). Is the SOGS an accurate measure of pathological gambling among children, adolescents and adults?. Journal of Gambling Studies, 16, pp. 1-24.

[12] Lesieur, H. R., \& Blume, S. B. (1987). The South Oaks Gambling Screen (SOGS): A new instrument for the identification of pathological gamblers. American Journal of Psychiatry, 144(9), pp.1184-1188. 
[13] Malczewski, A. (2011a). Młodzież i hazard [Youth and Gambling]. Remedium, 11, pp. 8-9.

[14] Malczewski, A. (2011b). Polacy a gry o charakterze hazardowym [Poles and Gambling Games]. Serwis Informacyjny NARKOMANIA, 3 (55), pp. 8-10.

[15] Malczewski, A. (2012). Uczestnictwo w grach hazardowych w Polsce - analiza sytuacji [Participation in Gambling Games in Poland - analysis of the situation]. Świat Problemów, 4, pp. 14-18.

[16] Malczewski, A. (2014). Uczestnictwo młodzieży i młodych dorostych w grach hazardowych [Participation of Youth and Young Adults in Gambling Games]. In: J. Jarczyńska (Ed.) Uzależnienia behawioralne $i$ zachowania problemowe młodzieży. Teoria-Diagnoza-Terapia. [Behavioral Addictions and Problem behavior of Youth. Theory-Diagnosis-Therapy]. Bydgoszcz: Wydawnictwo Uniwersytetu Kazimierza Wielkiego, pp. 109-120.

[17] Malczewski, A. (2011c). Zjawisko uczestnictwa w grach losowych o charakterze hazardowym [The Phenomenon of Participation in Gambling Games]. Świat Problemów, 7, pp. 23-26.

[18] Poulin, C. (2000). Problem gambling among adolescent students in the Atlantic provinces of Canada. Journal of Gambling Studies, 16 (1), pp. 53-78.

[19] Poulin, C. (2002). An assessment of the validity and reliability of the SOGS-RA. Journal of Gambling Studies, 18 (1), pp. 67-93.

[20] Shaffer, H.J., \& Hall, M.N. (1996). Estimating the prevalence of adolescent gambling disorders: A quantitative synthesis and guide toward standard gambling nomenclature. Journal of Gambling Studies, 12 (2), pp. 193-214.

[21] Shaffer, H.J., LaBrie, R.A., Scanlan, K.M., \& Cummings, T.N. (1994). Pathological gambling among adolescents: Massachusetts Gambling Screen. Journal of Gambling Studies, 10 (4), pp. 339-362.

[22] Sierosławski, J. (2011). Używanie alkoholu i narkotyków przez młodzież szkolna. Raport z ogólnopolskich badań ankietowych zrealizowanych w 2011 roku. Europejski Program Badań Ankietowych w Szkotach ESPAD [The Use of Alcohol and Drugs by School Youth. Report of the National Questionnaire Study in Poland Conducted in 2011. European School Survey Project on Alcohol and Drugs]. Warsaw: Instytut Psychiatrii i Neurologii.

[23] Skokauskas, N., Burba, B., \& Freedman, D. (2009). An assessment of the psychometric properties of Lithuanian versions of DSM-IV-MR-J and SOGS-RA.Journal of Gambling Studies, 25 (2), pp. 263-271.

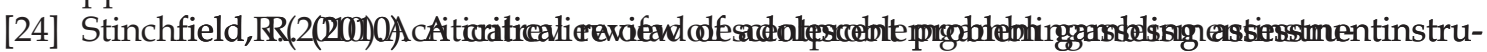
ments. International Journal of Adolescent Medicine And Health, 22 (1), pp. 77-93.

[25] Stinchfield, R. (2011). A critical review of adolescent problem gambling assessmentinstruments. In: J.L. Derevensky, D.T.L. Shek, \& J. Merrick (Eds.). Hazard Youth: The hidden addiction. Berlin/ Boston: Health, Medicine and Human Development, pp. 147-166.

[26] Stinchfield, R., Govani, R., \& Frisch, R.G. (2004). Screening and assessment instruments. In :J.E. Grant, \& M.N. Potenza (Eds.). A clinical guide to treatment. Washington, DC: American Psychiatric Publishing, INC., pp. 207-231.

[27] Westphal, J.R., Rush, J.A., Stevens, L., \& Johnson, L.J. (2000). Gambling behavior of Louisiana students in grades 6 through 12. Psychiatric Services, 51, pp. 96-99.

[28] Wiebe, J.M.D. (1999). Manitoba youth gambling prevalence study. Winnipeg: Addictions Foundation of Manitoba.

[29] Wiebe, J.M.D., Cox, B.J., \& Mehmel, B.G. (2000). The South Oaks Gambling Screen Revised for Adolescents (SOGS-RA): Further psychometric findings from a community sample. Journal of Gambling Studies, 16, pp. 275-288.

[30] Wiebe, J., Single, E., \& Falkowski-Ham, A. (2001). Measuring gambling and problem gambling in Ontario. Toronto, ON: Canadian Centre on Substance Abuse.

[31] Winters, K.C., Stinchfield, R., \& Fulkerson, J. (1993). Toward the development of an adolescent gambling problem severity scale. Journal of Gambling Studies, 9, pp. 63-84. 